\title{
Plant physiological and environmental controls over the exchange of acetaldehyde between forest canopies and the atmosphere
}

\author{
K. Jardine ${ }^{1, *}$, P. Harley ${ }^{2}$, T. Karl' ${ }^{2}$, A. Guenther ${ }^{2}$, M. Lerdau ${ }^{1, * *}$, and J. E. Mak ${ }^{1}$ \\ ${ }^{1}$ School of Marine and Atmospheric Sciences, Stony Brook University, Stony Brook, NY, USA \\ ${ }^{2}$ Earth and Sun Systems Laboratory, National Center for Atmospheric Research, Boulder, Colorado, USA \\ * now at: Biosphere 2, University of Arizona, Tucson, AZ, USA \\ ** now at: Department of Environmental Sciences, University of Virginia, Charlottesville, VA, USA
}

Received: 9 May 2008 - Published in Biogeosciences Discuss.: 25 June 2008

Revised: 11 September 2008 - Accepted: 25 September 2008 - Published: 19 November 2008

\begin{abstract}
We quantified fine scale sources and sinks of gas phase acetaldehyde in two forested ecosystems in the US. During the daytime, the upper canopy behaved as a net source while at lower heights, reduced emission rates or net uptake were observed. At night, uptake generally predominated throughout the canopies. Net ecosystem emission rates were inversely related to foliar density due to the extinction of light in the canopy and a respective decrease of the acetaldehyde compensation point. This is supported by branch level studies revealing much higher compensation points in the light than in the dark for poplar (Populus deltoides) and holly oak ( $Q$ uercus ilex) implying a higher light/temperature sensitivity for acetaldehyde production relative to consumption. The view of stomata as the major pathway for acetaldehyde exchange is supported by strong linear correlations between branch transpiration rates and acetaldehyde exchange velocities for both species. In addition, natural abundance carbon isotope analysis of gas-phase acetaldehyde during poplar branch fumigation experiments revealed a significant kinetic isotope effect of $5.1 \pm 0.3 \%$ associated with the uptake of acetaldehyde. Similar experiments with dry dead poplar leaves showed no fractionation or uptake of acetaldehyde, confirming that this is only a property of living leaves. We suggest that acetaldehyde belongs to a potentially large list of plant metabolites where stomatal resistance can exert long term control over both emission and uptake rates due to the presence of both source(s) and $\operatorname{sink}(\mathrm{s})$ within the leaf which strongly buffer large changes in concentrations in the substomatal airspace due to changes in stomatal resistance. We conclude that the exchange of acetaldehyde
\end{abstract}

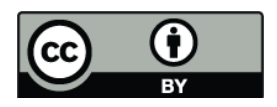

Correspondence to: $\mathrm{K}$. Jardine (jardine@email.arizona.edu) between plant canopies and the atmosphere is fundamentally controlled by ambient acetaldehyde concentrations, stomatal resistance, and the compensation point which is a function of light/temperature.

\section{Introduction}

Acetaldehyde is considered to be a hazardous air pollutant by the USEPA and can lead to the production of other harmful pollutants such as ozone and peroxyacetyl nitrates (PAN). As recently reviewed by Seco et al. (2007), significant quantities of acetaldehyde are emitted by plants to the atmosphere (Janson et al., 1999; Villanueva-Fierro et al., 2004; Hayward et al., 2004; Martin et al., 1999; Schade and Goldstein, 2001). However, the ability of plants to also act as a sink for acetaldehyde has become increasingly clear (Karl et al., 2005; Rottenberger et al., 2004). Our understanding of how environmental and plant physiological variables influence acetaldehyde exchange rates with the atmosphere is lacking. This is largely because information on the processes that produce and consume acetaldehyde in plants, the mechanism by which acetaldehyde exchanges with plants (cuticle, stomata, or surface), and the role of environmental variables such as light and temperature on these processes is limited. Unless these controlling factors are clearly understood, a quantitative understanding of the role of the biosphere in the tropospheric budget of acetaldehyde will not be possible.

The metabolism of acetaldehyde in plants is uncertain although it is known that during anoxic conditions, ethanol produced from ethanolic fermentation in roots is transported to leaves via the transpiration stream, where it is oxidized to acetaldehyde (Kreuzwieser et al., 2004). This is a potentially

Published by Copernicus Publications on behalf of the European Geosciences Union. 
significant source of acetaldehyde to the atmosphere for example during the wet season in the Amazon forest, where roots are regularly flooded (Rottenberger et al., 2008). Using excised branches, Jardine (2008) suggested that ethanolic fermentation may also be active in leaves under aerobic conditions. Emission rates of ethanol, acetaldehyde, and acetic acid from excised poplar branches were light/temperature dependent with strong emission bursts occurring upon darkening. The strong correlations between acetaldehyde and acetic acid emissions indicated a rapid conversion of acetaldehyde to acetic acid as a part of the pyruvate dehydrogenase (PDH) bypass system. Therefore, the activation of acetaldehyde to acetyl CoA by the PDH bypass system appears to be an effective sink for ethanolic fermentation products produced within leaves and other tissues as well as atmospheric acetaldehyde.

Because plants both produce and consume acetaldehyde, exchange with the atmosphere can proceed in either direction. For all leaves, there exists a compensation point (Kesselmeier, 2001) defined as the ambient concentration at which the net exchange between a plant and the atmosphere is zero. When the ambient acetaldehyde concentration is below the compensation point, acetaldehyde is emitted from leaves; when ambient levels exceed the compensation point, it is taken up. Compensation points reflect the relative rates of production and consumption processes within plants; when production predominates, the compensation point is high, and vice versa. Unfortunately, acetaldehyde compensation point measurements are extremely rare. At the low end, compensation points for two drought deciduous Amazonian tree species in the field during the wet season were $0.56 \mathrm{ppbv}$ (Hymenaea courbaril) and $0.32 \mathrm{ppbv}$ (Apeiba tibourbou) (Rottenberger et al., 2004). At the high end, from fumigation studies on potted Norway Spruce, Cojocariu et al. (2004) found the acetaldehyde compensation point is about 6 ppbv. While species composition and leaf age may have some influence on compensation point (Rottenberger et al., 2005), recent evidence suggests that environmental variables like temperature are also important (Karl et al., 2005). Acetaldehyde compensation points for potted Loblolly Pine (Pinus taeda) increased from $2.5 \mathrm{ppbv}$ at $25^{\circ} \mathrm{C}$ to $4.3 \mathrm{ppbv}$ at $30^{\circ} \mathrm{C}$, implying that production is more sensitive to temperature than consumption in plants.

Within-canopy flux studies of acetaldehyde are also extremely rare, but experiments measuring concentration gradients have been used to imply a flux. For example in Germany, Muller et al. (2006) measured lower concentrations within the canopy than above the canopy. They attributed this to emissions and photochemical production of acetaldehyde in the upper canopy and deposition in the lower canopy. Rottenberger et al. (2004) measured similar vertical concentration profiles in the Amazon and attributed them to photochemical production above the canopy and strong uptake by the vegetation within the canopy. From direct measurements of acetaldehyde exchange rates using branch enclosures, Cojocariu et al. (2004) found that acetaldehyde was emitted by spruce (Picea abies) trees in the field and that the emission rates increased with height in the canopy. Karl et al. (2005) determined the structure of the fields of acetaldehyde concentration and air turbulence in North Carolina, US, and using an inverse Lagrangian dispersion model (Raupach, 1989) were able to characterize the sources and sinks within the canopy. The results show emissions at the top of the canopy during daytime with strong uptake within the canopy with the highest uptake coinciding with the highest leaf area index.

The pattern of net emissions in the upper canopy and net uptake deeper within the canopy cannot be explained assuming a fixed acetaldehyde compensation point because the ambient concentrations were higher in the upper canopies than in the lower canopies. Were compensation points constant, this would tend to increase uptake rates in the upper canopies and emissions from the lower canopies. Therefore, it is likely that diurnal trends of radiation and temperature influence the rates of acetaldehyde production and consumption in plants, thus determining the compensation point. Supporting this idea, several studies show a clear diurnal emission pattern from plants in both laboratory and field settings (Cojocariu et al., 2005; Schade and Goldstein, 2001; Karl et al., 2003, 2002b; Kreuzwieser et al., 2000). In addition, a strong relationship between acetaldehyde emission rates and temperature (Hayward et al., 2004; Schade and Goldstein, 2002; Cojocariu et al., 2004) and light (Kreuzwieser et al., 2000; Kondo et al., 1998) has been observed.

In addition to production and consumption processes, the exchange mechanism(s) of acetaldehyde between plants and the atmosphere is uncertain. During fumigation experiments with extremely high concentrations of acetaldehyde, Kondo et al. (1998) observed that trees with higher transpiration rates had higher uptake rates and when light levels were varied, a linear relationship was discovered between transpiration rates and uptake rates. Uptake was measured continuously for up to $8 \mathrm{~h}$ at ambient concentrations as high as $3000 \mathrm{ppbv}$ with no visible damage to the plants. This strongly suggests that a biological removal process mediated by plant stomata rather than plant cuticles was responsible for uptake since a continuous removal process is required for such a large and sustained sink. In addition, chemical reactions with the leaf surface are unlikely since the surface is mainly composed of inert alkanes (waxes). In a series of studies in the Amazon, acetaldehyde exchange measurements and resistance modeling suggested that while stomatal exchange dominates, acetaldehyde deposition to leaf cuticle can be a significant atmospheric sink (Rottenberger et al., 2004, 2005, 2008). By regressing the ambient acetaldehyde concentrations $\left(\mathrm{g} \mathrm{m}^{-3}\right)$ against the acetaldehyde exchange flux $\left(\mathrm{g} \mathrm{m}^{-2} \mathrm{~s}^{-1}\right)$, two important pieces of information were obtained. The first is the compensation point ( $\mathrm{x}$-intercept, $\mathrm{g} \mathrm{m}^{-3}$ ) and the second is the slope defined as the acetaldehyde exchange velocity $v_{e}\left(\mathrm{~m} \mathrm{~s}^{-1}\right)$. 
Confusingly, many studies indicate a lack of stomatal influence on exchange rates. For example, several studies concluded that acetaldehyde emissions were not correlated with any physiological parameters including stomatal conductance (Kesselmeier et al., 1997; Kesselmeier, 2001; Martin et al., 1999). When ethanol was supplied to poplar leaves, promoting production of acetaldehyde in a reaction catalyzed by alcohol dehydrogenase, no correlation could be found between stomatal conductance and acetaldehyde emissions, where variation in conductance was induced either by abscisic acid or by varying light (Kreuzwieser et al., 2001). The authors concluded that acetaldehyde emissions are primarily controlled by biochemical production mechanism within the plant.

In this study, we compare the results from Karl et al. (2005) with new in-canopy source/sink estimates and interpret them in light of process-based laboratory studies. In order to investigate the role of light/temperature on branch level acetaldehyde exchange rates, ambient acetaldehyde concentrations were varied over a wide range (0-30 ppbv) and compensation points were determined in the dark and the light. The effect of stomatal resistance was investigated by measuring branch level transpiration rates which varied from branch to branch and from dark to light conditions. In addition, to better understand the role of stomatal resistance on the exchange of acetaldehyde with the atmosphere, the carbon isotope composition of gas phase acetaldehyde was studied during branch fumigation experiments. It is well known that during photosynthesis, carbon dioxide uptake occurs exclusively through the stomata. During this process, the "heavier" isotopologues of carbon dioxide containing ${ }^{13} \mathrm{C}$ are discriminated against (see review by Farquhar et al., 1989). The major components of the discrimination are physical and chemical kinetic fractionation processes, including diffusion through plant stomata and within the plant and carboxylation reactions. We hypothesized that if plant stomata are the dominant pathway of acetaldehyde exchange, then the heavy isotopologues of acetaldehyde will also be discriminated against during uptake. We further hypothesized that the fractionation is only due to diffusional processes and not to chemical processes such as the oxidation of acetaldehyde to acetate. If this is the case, the kinetic isotope effect should be on the same order as that for diffusion of acetaldehyde in air. Assuming that once the acetaldehyde enters the plant it is not returned to the atmosphere, then the kinetic isotope effect due to diffusion in air can be estimated according to Eq. (1) adopted from Johnson and Dawson (1993).

$\alpha=\sqrt{\frac{\text { M44+Mair }}{\text { M45 } \times \text { Mair }} \times \frac{\text { M45 } \times \text { Mair }}{\text { M45+Mair }}}$

Where M44, M45, and Mair represent the molecular weight of the acetaldehyde isotopes and air, respectively. The value for $\alpha$ in this case is 1.0044 corresponding to a $4.4 \%$ fractionation. In other words, at steady state the acetaldehyde remaining in the air stream passing over a branch should be
$4.4 \%$ more enriched in ${ }^{13} \mathrm{C}$ than the initial source. Therefore, if the measured kinetic isotope effect during the uptake of acetaldehyde is near $4.4 \%$ o this would provide strong evidence to support the role of stomatal exchange. If dry deposition onto the surface of leaves were the dominant mode of acetaldehyde deposition to plants, it might also fractionate the acetaldehyde in a similar manner due to molecular diffusion through the stagnant air near the leaf surface (boundary layer resistance, $R_{b}$ ). However, this may only be a temporary sink since an equilibrium may be quickly established where no net deposition or emission occurs. Therefore, long term uptake and fractionation would indicate a stomatal sink. We employ dry dead leaves which possess similar surface area but lack a biochemical sink mechanism to help discriminate between physical and biological processes. If deposition to external surfaces dominates acetaldehyde removal, then similar uptake rates and associated kinetic isotope effects should be observed for both live and dead poplar branches.

\section{Methods}

\subsection{Plants}

Potted poplar individuals (Populus deltoides, clone \#ST109) used for estimating the kinetic isotope effect associated with acetaldehyde uptake were obtained from the Stony Brook University greenhouse. Additional poplar (Populus deltoides, S7c8 East Texas Day Neutral clone) and holly oak (Quercus ilex) individuals used for acetaldehyde compensation point studies were obtained from the National Center for Atmospheric Research greenhouse, (Boulder, CO). Plants were potted into 4-L plastic pots containing a commercial potting mix (MiracleGro) with Osmocote slow release fertilizer.

\subsection{Compensation point measurements}

Branch level acetaldehyde fluxes and compensation point determinations were made using a $5.0 \mathrm{~L}$ dynamic branch enclosure constructed of Teflon. Hydrocarbon free air was introduced into the enclosure through a mass flow controller (OMEGA Engineering, Stamford, Connecticut) at a flow rate of $1.0 \mathrm{~L} \mathrm{~min}^{-1}$, resulting in an enclosure residence time of approximately $5 \mathrm{~min}$. For acetaldehyde concentration measurements, approximately $200 \mathrm{ml} \mathrm{min}^{-1}$ of sample air was continuously drawn out of the enclosure and into a proton transfer reaction mass spectrometer (PTR-MS) through $1 / 8^{\prime \prime}$ Teflon tubing. The PTR-MS instrument has been described in detail elsewhere (Lindinger and Hansel, 1997). Mass to charge ratio 45 , corresponding to the protonated form of acetaldehyde, was monitored with a 30-s dwell time. In addition, mass to charge ratio 37 , corresponding to the protonated cluster of two water molecules, was monitored with a $0.1-\mathrm{s}$ dwell time. This signal is very sensitive to water vapor concentrations (Ammann et al., 2006), allowing us to estimate 
transpiration rates. During branch compensation point measurements, $0-15 \mathrm{ml} \mathrm{min}^{-1}$ of a $2.0 \mathrm{ppmv}$ acetaldehyde standard $( \pm 10 \%$ accuracy) was added to the hydrocarbon free air stream to generate acetaldehyde concentrations between 0 and $30 \mathrm{ppbv}$. The mixture was added to the branch enclosure and an automated Teflon valve was used to switch between sampling the air before and after the enclosure. The air before the enclosure was used to calibrate the acetaldehyde concentration measurements by regressing the incoming acetaldehyde concentrations against the signal at $\mathrm{m} / \mathrm{z} 45$ normalized to $\mathrm{m} / \mathrm{z} 21$. The sample switching valve was programmed to switch after every ten PTR-MS measurement cycles $(\sim 10 \mathrm{~min})$. During one cycle, the mass to charge ratios 21,37 , and 45 were sequentially measured $(\sim 1 \mathrm{~min})$. The net exchange flux of acetaldehyde was calculated using Eq. (2),

Flux $=\frac{\left(\mathrm{ppbv}_{\mathrm{after}}-\mathrm{ppbv}_{\mathrm{before}}\right) \cdot \text { Flow } \cdot P}{\mathrm{gdw} \cdot R \cdot T} \cdot \frac{10^{-9} \mathrm{~mole}}{\text { nanomole }} \cdot \frac{44 g}{\mathrm{~mole}}$

where Flux is the net flux rate in $\mathrm{g} \mathrm{gdw}^{-1} \mathrm{hr}^{-1}$, Flow is the total flow rate entering the enclosure in $\mathrm{L} \mathrm{hr}^{-1}, P$ is the atmospheric pressure in atmospheres, $\mathrm{gdw}$ is the dry leaf weight, $R$ is the universal gas constant $\left(0.08206 \mathrm{Latm} \mathrm{K}^{-1} \mathrm{~mol}^{-1}\right)$, and $T$ is the air temperature in Kelvin. The total relative error in calculating the concentration difference $E \Delta C / \Delta C$ is the sum of errors associated with uncertainty in the concentration of the standard and the precision of the concentration measurements (Eq. 3).

$$
\begin{aligned}
\frac{E_{\Delta C}}{\Delta C}= & \sqrt{\left(\frac{E_{\text {after }}}{\Delta C}\right)^{2}+\left(\frac{E_{\text {before }}}{\Delta C}\right)^{2}} \text { calibration } \\
& +\frac{\sqrt{E_{\text {after }}^{2}+E_{\text {before }}^{2}}}{\overline{\Delta C}} \text { measurement }
\end{aligned}
$$

The relative error for each concentration calculation due to uncertainty in the concentration of the standard is set to $10 \%$ (calibration error). The measurement error is the standard deviation of the concentration measurements during each measurement period. The absolute error in the calculated exchange rates $\left(E_{e x}\right.$, in $\left.\mathrm{g} \mathrm{gdw}^{-1} \mathrm{hr}^{-1}\right)$ is calculated according to the error propagation method (Eq. 4). The relative errors were set to enclosure flow rate $\left(E_{F} /\right.$ Flow $\left.=0.10\right)$, pressure $\left(E_{P} / P=0.10\right)$, temperature $\left(E_{T} / T=0.10\right)$, and the leaf dry weight $\left(E_{\mathrm{gdw}} / \mathrm{gdw}=0.005\right)$.

$E_{e x}=$ Flux $\sqrt{\left(\frac{E_{\Delta C}}{\Delta C}\right)^{2}+\left(\frac{E_{\text {Flow }}}{\text { Flow }}\right)^{2}+\left(\frac{E_{P}}{P}\right)^{2}+\left(\frac{E_{\text {gdw }}}{g d w}\right)^{2}+\left(\frac{E_{T}}{T}\right)^{2}}$

Acetaldehyde emissions thus represent a positive flux, while deposition to the leaf is represented as a negative flux. The flux was allowed to stabilize for one hour before switching to the next concentration. Once the concentrations stabilized, the PTR-MS signals were averaged and the difference in concentrations between the incoming and outgoing air was calculated. Acetaldehyde exchange velocities $\left(\mathrm{g} \mathrm{gdw}^{-1} \mathrm{ppbv}^{-1} \mathrm{hr}^{-1}\right.$ ) were estimated by determining the slope of the regression of the acetaldehyde exchange flux in $\mathrm{g} \mathrm{gdw}^{-1} \mathrm{hr}^{-1}$ (y-axis) against acetaldehyde concentrations at the enclosure inlet in ppbv (x-axis). The acetaldehyde exchange velocities are reported as negative values of the slopes (all slopes were negative). Compensation points in ppbv were estimated by determining the $\mathrm{x}$-intercept of the same regression. Although leaf area was not measured, a specific leaf mass of $100 \mathrm{~g} \mathrm{~m}^{-2}$ was used to convert estimated exchange velocities from units of $\mathrm{g} \mathrm{gdw}^{-1} \mathrm{ppbv}^{-1} \mathrm{hr}^{-1}$ to $\mathrm{m} \mathrm{s}^{-1}$ for both holly oak and poplar branches. Although the exchange velocities reported here in $\mathrm{m} \mathrm{s}^{-1}$ can only be considered as rough estimates due to uncertainties in the specific leaf mass used for the unit conversion, they were done in order to compare the exchange velocity estimates made here with previously published estimates in $\mathrm{m} \mathrm{s}^{-1}$ (Rottenberger et al., 2004, 2005, 2008). Light was supplied by a 1000-W high intensity metal halide discharge lamp (Sylvania MS1000-M47) with an intensity of photosynthetically active radiation at branch height of roughly $1000 \mu \mathrm{mol} \mathrm{m}^{-2} \mathrm{~s}^{-1}$. Air temperatures inside the enclosure were measured with a K-type thermocouple (OMEGA Engineering, Stamford, CT) and ranged between $24-25^{\circ} \mathrm{C}$ in the dark and from $29-32^{\circ} \mathrm{C}$ in the light. For dark measurements, the lamp was turned off and the branch enclosure was covered with aluminum foil. Compensation point measurements were performed on four poplar branches in the light and six in the dark. For holly oak, five compensation point measurements were performed in the light and one in the dark.

\subsection{Estimating the kinetic isotope effect associated with ac-} etaldehyde uptake

To estimate the kinetic isotope effect associated with the uptake of acetaldehyde by poplar branches, a $39.2 \mathrm{ppbv}$ acetaldehyde standard was generated by mixing $0.5 \mathrm{~L} \mathrm{~min}^{-1}$ of commercial UHP hydrocarbon free air with $10 \mathrm{ml} \mathrm{min}^{-1}$ of a $2.0 \mathrm{ppmv}$ acetaldehyde standard. This mixture was introduced into a $5 \mathrm{~L}$ dynamic branch enclosure made of Teflon and had a residence time of $\sim 10 \mathrm{~min}$. A gas chromatography-combustion-isotope ratio mass spectrometer (GC-C-IRMS) system with a custom cryogenic VOC preconcentration system as described in Jardine (2008) was used to alternately analyze the stable carbon isotope composition of acetaldehyde before and after the dynamic branch enclosure. After obtaining several blank samples without a branch ( $\sim 30 \mathrm{~min} / \mathrm{sample}$ ), the poplar branch was introduced into the enclosure. Although the branch was exposed to only the very low light levels of room light, transpiration rates were not zero as evidenced by the large amount of water trapped in the water trap. Control experiments were also performed with dry dead poplar leaves. The precision of the instrument (one standard deviation) was calculated from repeated measurements of the $39.2 \mathrm{ppbv}$ standard to be between $0.2 \%$ and $1.0 \%$. 
The kinetic isotope fractionation factor $\alpha$ associated with the uptake of acetaldehyde was determined as in Miller et al. (2001) from the slope $(b)$ of the regression of $\delta^{13} \mathrm{C}$ values of the remaining reactant acetaldehyde on the natural logarithm of the fraction of remaining reactant $(\ln f)$ using Eqs. (5-6). The subscripts $r f$ and $r o$ refer to the reactant at $f$ and the initial reactant. It is then reported as $\varepsilon$, the deviation from unity using Eq. (7) in units of per mil (\%o). The quantity $f$ was calculated from the acetaldehyde peak areas before and after the enclosure using Eq. (8), where PA is the acetaldehyde derived carbon dioxide peak area for $\mathrm{m} / \mathrm{z} 44$ as measured by GC-C-IRMS for samples before and after the enclosure.

$b=\frac{\delta^{13} C_{r f}-\delta^{13} C_{r o}}{\ln f}$

$\alpha=\frac{1000}{b+1000}$

$\varepsilon=(\alpha-1) \cdot 1000$

$f=\frac{P A_{\text {after }}}{P A_{\text {before }}}$

\subsection{Canopy scale gradients}

Continuous vertical gradients of acetaldehyde concentrations were obtained at a hardwood forest in northern Michigan at the PROPHET Tower (at the University of Michigan Biological Station, UMBS), between 25 July and 14 August 2005. Similar measurements were obtained in 2007 at a walnut orchard in central California as a part of the Canopy Horizontal Array Turbulence Study field experiment $\left({ }^{1} \mathrm{CHATS}\right)$ from 10 May to 15 June. At both field sites, a Proton-TransferReaction Mass Spectrometer was used for gradient measurements of selected VOCs including acetaldehyde. Acetaldehyde concentrations could be measured at $\mathrm{m} / \mathrm{z} 45$ with an accuracy of $\pm 20 \%$ and a detection limit of 50 pptv for a $5 \mathrm{~s}$ integration time. The instrument was operated at 2.3 mbar drift pressure and $540 \mathrm{~V}$ drift voltage and calibrated using a multicomponent ppmv VOC standard (Apel-Riemer Inc., Denver, $\mathrm{CO})$.

In California, the instrument sequentially sampled six independent $1 / 4^{\prime \prime}$ inch Teflon (PFA) sampling lines mounted at $1.5,4.5,9,11,14$ and $23 \mathrm{~m}$ on a $30 \mathrm{~m}$ tall tower. A valve switching system changed sampling lines every 5 min giving a complete profile every $30 \mathrm{~min}$. Gradients were calculated from the $5 \mathrm{~min}$ averages. High flow rates through the sampling lines resulted in delay times of less than 8-12 s, measured by spiking a VOC pulse at each sampling inlet.

At UMBS (see Karl et al., 2003 for details of this site), air was pulled through a single Teflon line $\left(\right.$ O.D. $\left.=1 / 4^{\prime \prime}\right)$ on the sampling tower at a high flow rate $\left(\sim 15 \mathrm{~L} \mathrm{~min}^{-1}\right)$, reducing the pressure inside the line to $400 \mathrm{mbar}$ in order to avoid

\footnotetext{
${ }^{1}$ http://www.eol.ucar.edu/rtf/projects/CHATS/isff/
}

water condensation, minimize memory effects and assuring a fast response time. The overall delay time was $\sim 6 \mathrm{~s}$, measured by introducing an isoprene and acetone pulse at the top of the tower. The gradient sampling inlet line was attached to a pulley controlled by an automated winch, and ambient acetaldehyde concentrations were made continuously between $7.5 \mathrm{~m}$ and $28.5 \mathrm{~m}$ height. The canopy line moved at a constant speed of $0.2 \mathrm{~m} / \mathrm{s}$ resulting in a complete profile approximately every $1.75 \mathrm{~min}$. Source/sink profiles for both field sites were computed according to Eq. (9),

$C-C_{\text {ref }}=\stackrel{\leftrightarrow}{D} \cdot S$

with $\boldsymbol{C}$ (concentration vector), $C_{\text {ref }}$ (concentration at top of canopy), D (dispersion matrix) and $\boldsymbol{S}$ (source/sink vector) (Karl et al., 2003). Parameterization of the dispersion matrix (21 concentration layers and 5 source/sink layers) was based on an inverse Lagrangian model (Raupach, 1989) and measured turbulence profiles.

\section{Results}

\subsection{Branch results}

Figures 1 and 2 illustrate acetaldehyde exchange as a function of the incoming concentrations (inlet) for poplar and holly oak branches, respectively. When acetaldehyde-free air was used, emissions were observed from all branches. Increasing the acetaldehyde concentration entering the enclosure invariably resulted in a reduction in emission rates and eventually to net uptake of acetaldehyde in many cases. The concentration at which the net flux is zero represents the compensation point. In the dark, the acetaldehyde compensation point for poplar branches was between 1 and 3 ppbv. Measurements in the light showed much higher compensation points ( $>12 \mathrm{ppbv})$. The variability of acetaldehyde compensation points seen for the different branches in the light may partly be due to the variable amount of enclosed biomass (1.0-7.0 gdw) which likely resulted in a variable amount of leaf shading. Similar measurements on holly oak branches revealed a similar pattern in the light with very high compensation points $(>22 \mathrm{ppbv})$. In the single dark measurement, acetaldehyde exchange rates were very low and the precise compensation point was difficult to determine. Secondary photochemical production of acetaldehyde in the enclosure is unlikely because the inlet of the enclosure was supplied with hydrocarbon free air produced by passing room air through a catalytic converter heated to $400^{\circ} \mathrm{C}$. As such, the $\mathrm{OH}$ and ozone concentrations were likely to be very low due to a lack of $\mathrm{NO}_{\mathrm{x}}$ chemistry. While some secondary photochemical production from terpene oxidation can produce acetaldehyde, the yields are quite low. For example, Lee et al. (2006b) investigated the products of photooxidation of 16 different terpenes including isoprene, 8 monoterpenes, 

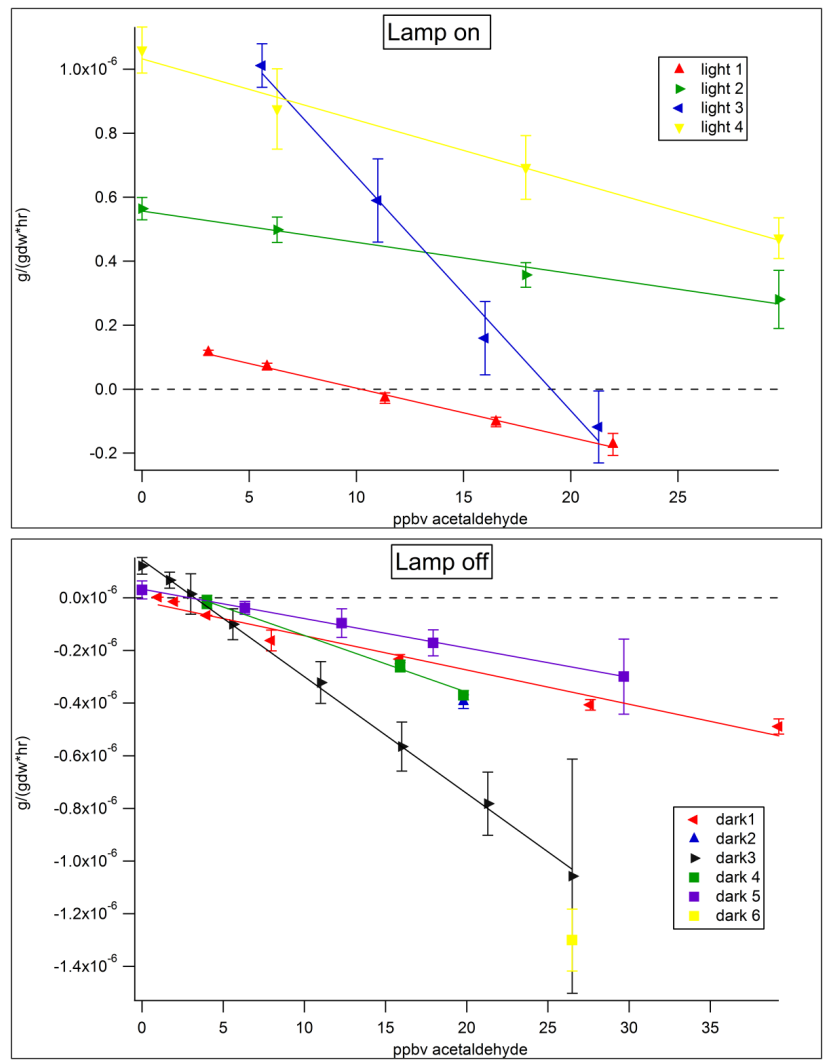

Fig. 1. Example of compensation point measurements for acetaldehyde with Poplar branches (Populus deltoides) measured by PTRMS during light and dark conditions. Branch level flux measurements (y-axis) are plotted versus incoming acetaldehyde concentrations (x-axis).

3 oxygenated terpenes, and 4 sesquiterpenes including $\beta$ Caryophyllene. The measured acetaldehyde yields ranged between $0.2 \%$ and $2.9 \%$ with $\beta$-Caryophyllene having an intermediate value of $1.6 \%$. When similar experiments were carried out to specifically investigate the ozonolysis of gas phase terpenes, acetaldehyde yields ranged from $0.9 \%$ to $15 \%$ with $\beta$-Caryophyllene having a low value of $0.9 \%$ (Lee et al., 2006a). Therefore, the high compensation points measured in the light are likely due to higher plant production rates in the light than in the dark.

The slope of the relationship between acetaldehyde exchange rate and incoming acetaldehyde concentration is defined as the exchange velocity. As depicted in Figs. 3 and 4 , a strong linear correlation between branch transpiration rates and exchange velocities was found for both species. While acetaldehyde exchange velocities tended to be smaller for holly oak than for poplar (Fig. 5), so did transpiration rates. For example, while poplar branches maintained nonzero transpiration rates and therefore significant acetaldehyde exchange velocities in the dark, holly oak branches displayed very low transpiration and acetaldehyde exchange

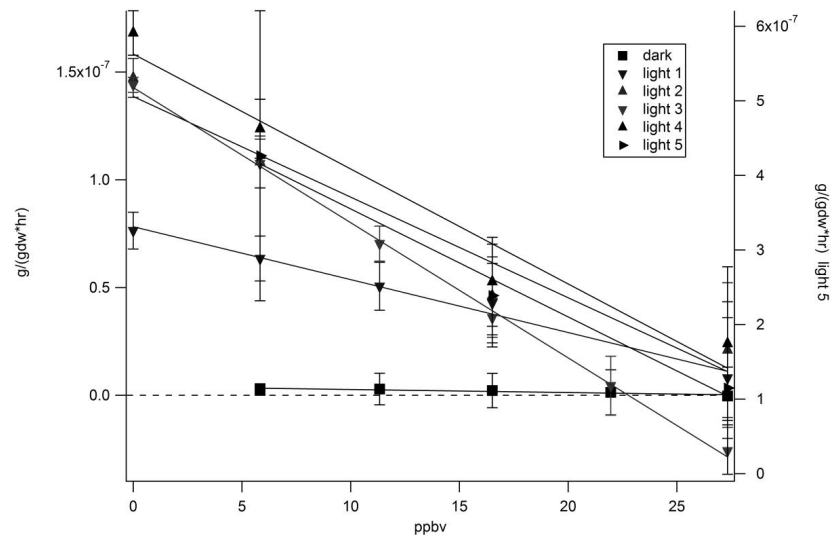

Fig. 2. Example of compensation point measurements for acetaldehyde with Holly Oak branches (Quercus ilex) measured by PTR-MS during light and dark conditions. Branch level flux measurements (y-axis) are plotted versus incoming acetaldehyde concentrations (x-axis).

velocities in the dark. When compared with exchange velocities estimated for poplar, Rottenberger et al. (2004, 2005, 2008) reported two comparable and three higher acetaldehyde exchange velocities for Amazonian canopy and understory species (Fig. 5).

During fumigation experiments where the carbon isotopic composition of headspace acetaldehyde was measured by GC-C-IRMS, dry dead poplar leaves did not take up any of the $39.5 \mathrm{ppbv}$ acetaldehyde passing through the enclosure (Fig. 6, top row). In addition, the isotopic composition of acetaldehyde was not affected during its passage through the enclosure. In contrast, when a live poplar branch was placed in the enclosure, strong acetaldehyde uptake and carbon isotope fractionation occurred (Fig. 6, second row). The acetaldehyde remaining in the headspace became enriched in ${ }^{13} \mathrm{C}$ over time signifying the preferential uptake of the lighter acetaldehyde isotopologues by the poplar branch $\left(\mathrm{CH}_{3} \mathrm{CHO}\right.$ over ${ }^{13} \mathrm{CH}_{3} \mathrm{CHO}, \mathrm{CH}_{3}^{13} \mathrm{CHO}$, and $\left.{ }^{13} \mathrm{CH}_{3}^{13} \mathrm{CHO}\right)$. The second experiment was designed to test the ability of poplar branches to act as a long term sinks for acetaldehyde in order to help discriminate between stomatal uptake and a physical dry deposition process (Fig. 6, third row). A surface dry deposition process would be expected to eventually saturate the leaf surface and subsequently establish an equilibrium condition, following which the branch would no longer act as a net sink. The branch remained a strong sink for acetaldehyde for over $15 \mathrm{~h}$ with continuous carbon isotope fractionation of acetaldehyde.

Data from two branch measurements were pooled and a kinetic isotope effect was calculated to be to be $5.1 \pm 0.3 \%$ o (Fig. 7). At steady state conditions, the fraction of the gas phase acetaldehyde remaining was $\sim 0.4$ in both experiments which is close to the ideal value of 0.5 needed to minimize 


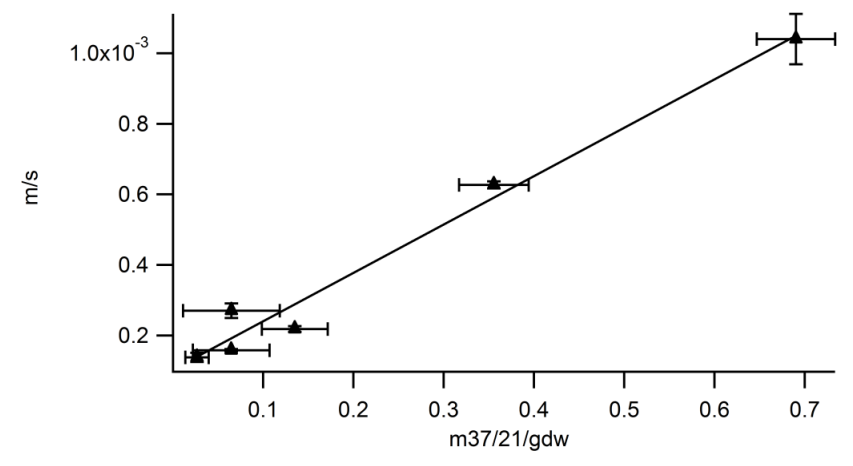

Fig. 3. Measured acetaldehyde exchange velocities for Poplar branches are related to transpiration rates. Branch level exchange velocities (y-axis) are plotted versus estimated PTR-MS transpiration rates ( $\mathrm{x}$-axis).

errors in kinetic isotope effect (KIE) calculations based on the analysis of the remaining reactant. The calculated KIE associated with the uptake of acetaldehyde by poplar branches $(5.1+/-0.3 \%$ o $)$ is close to the theoretical KIE occurring due to diffusion in air $(4.4 \%$ ). Therefore, assuming that no fractionation occurs during the oxidation of acetaldehyde within leaves, we can conclude that fractionation during diffusion in air is the most important process that determines the overall KIE associated with the uptake of acetaldehyde by poplar branches. In analogy with what is known about carbon dioxide during photosynthesis, if stomatal uptake is the dominate pathway for acetaldehyde exchange then the KIE during the diffusion of acetaldehyde into leaves can be described by $\mathrm{KIE}=\left(1-C_{o} / C_{a}\right) a$, where $C_{a}$ is the ambient concentration of $\mathrm{CO}_{2}\left(\mathrm{~g} \mathrm{~m}^{3}\right)$ and $C_{o}$ is the intercellular concentration of $\mathrm{CO}_{2}\left(\mathrm{~g} \mathrm{~m}^{3}\right)$ at the site of oxidation, and $a$ is the fractionation occurring due to diffusion in air (Farquhar et al., 1989). During net uptake, increasing stomatal resistance should tend to decrease $C_{o} / C_{a}$ while decreasing stomatal resistance should tend to increase it. Therefore, a higher stomatal resistance should lead to a larger KIE while a lower stomatal resistance should lead to a lower KIE. Future work using $\mathrm{ABA}$ or low light levels as used in this study with poplar branches to induce partial stomatal closure should attempt to verify this important prediction if stomatal uptake is indeed the dominant exchange mechanism between plants and the atmosphere. Ideally, future studies investigating the role of stomatal versus surface exchange of acetaldehyde would investigate the influence of stomatal resistance on both the KIE associated with uptake of acetaldehyde and the acetaldehyde exchange velocity.

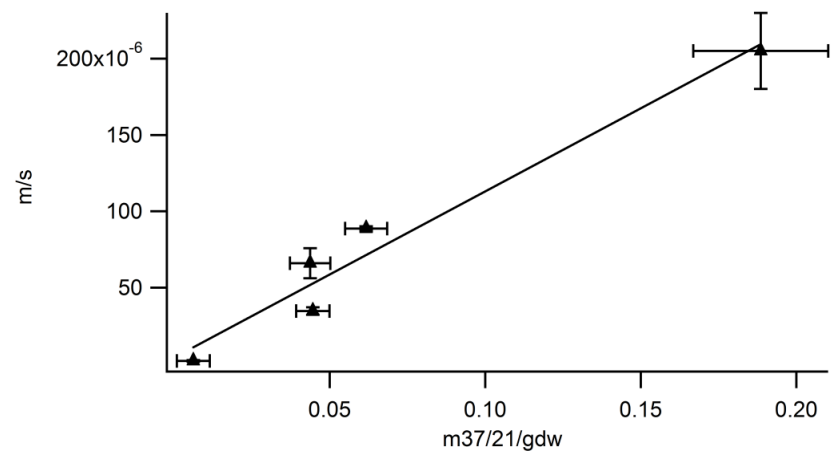

Fig. 4. Measured acetaldehyde exchange velocities for Holly Oak branches are related to transpiration rates. Branch level exchange velocities (y-axis) are plotted versus estimated PTR-MS transpiration rates ( $\mathrm{x}$-axis).

\subsection{Canopy results}

Average ambient acetaldehyde concentrations were separated into daytime (07:00-19:00 LT) and night time components (19:00-07:00 LT) and show clear vertical gradients in California, Michigan, and North Carolina (Fig. 8). During the daytime in Michigan, the average concentration was highest at $28.5 \mathrm{~m}$ and steadily declined within the canopy. A similar pattern was observed in North Carolina during the daytime where the average concentration was highest at $18.6 \mathrm{~m}$ and steadily declined within the canopy. In contrast, the walnut orchard in California displayed a different concentration profile during the day. The lowest concentration occurred at a height of $23 \mathrm{~m}$ and increased within the canopy. However, at night the concentrations in all field sites decreased with decreasing height. Although different background levels of acetaldehyde existed at each site, the maximum change in concentration throughout the canopies during the day or night was small $(<0.1 \mathrm{ppbv})$.

During the daytime, when the fine scale source/sink distributions of acetaldehyde were estimated by inverse modeling, similar patterns emerged between the three canopies at the top, but showed important differences deeper in the canopies (Fig. 8). Corresponding with the first appearance of significant leaf area index (LAI) at the top of the canopies, a strong net emission of acetaldehyde occurred. The magnitude of these net emissions declined with decreasing height in the canopies. In California, the emissions declined to near zero near the ground $(1.5 \mathrm{~m})$. However, in the denser canopies of Michigan and North Carolina, a transition to a net sink occurred. With an additional decrease in canopy height, the magnitude of the net sink decreased to near zero in both Michigan and North Carolina. At night, the canopies mainly behaved as a net sink although small emissions were detectable from the understory in North Carolina. 


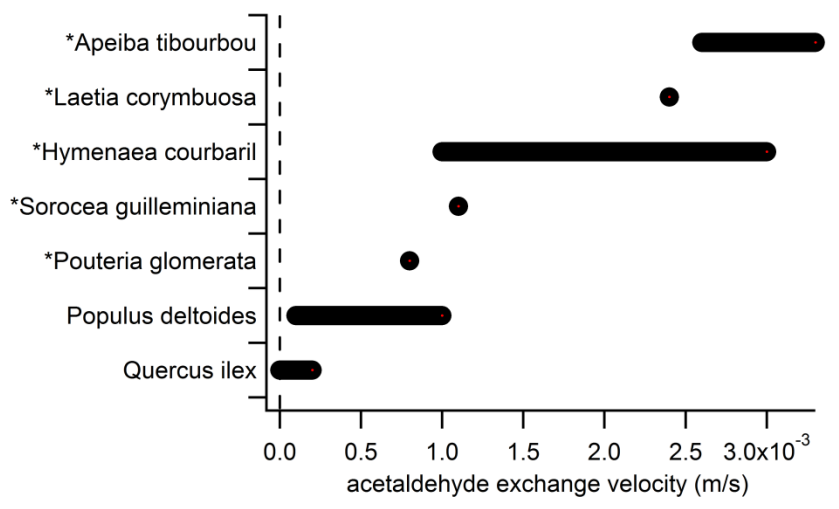

Fig. 5. Ranges (min, max) of acetaldehyde exchange velocities $(\mathrm{m} / \mathrm{s})$ estimated from this study $(Q$. ilex and $P$. deltoids) and *Rottenberger et al. (2004, 2005, 2008) (P. glomerata, S. guilleminiana, H. courbaril, L. corymbuosa, and A. tibourbou).

In our field experiments, we do not see evidence of significant photochemical production of acetaldehyde above the canopies, but we acknowledge that some photochemical production via long-lived precursors transported to the site could be possible. Within the canopies, the secondary photochemical production of acetaldehyde from reactive terpene species does not appear to be a significant source of acetaldehyde. For example in North Carolina during the same experiment reported in this paper (CELTIC), Stroud et al. (2005) used a one-dimensional canopy model to quantify the impact of photochemistry in modifying biosphereatmosphere exchange of trace gases. The estimated loss rates of $\beta$-Caryophyllene due to ozonolysis throughout the canopy during the day ranged between 10 and $140 \mathrm{pptv} \mathrm{min}^{-1}$. Us-

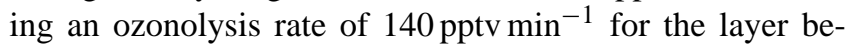
tween $15 \mathrm{~m}$ and $20 \mathrm{~m}$ and assuming a $2 \%$ acetaldehyde yield, the maximum acetaldehyde production rate within the canopy was $1.7 \times 10^{-3} \mathrm{mg} \mathrm{m}^{-2} \mathrm{hr}^{-1}$. Using the inverse Lagrangian model, we estimate that this layer $(15 \mathrm{~m}$ to $20 \mathrm{~m}$ ) corresponds to a strong net source of acetaldehyde of $8.0 \times 10^{-1} \mathrm{mg} \mathrm{m}^{-2} \mathrm{hr}^{-1}$, over one order of magnitude larger than the estimated rate of acetaldehyde production from $\beta$ Caryophyllene ozonolysis. Therefore, the secondary production of acetaldehyde within the canopy from the gas phase oxidation of reactive terpenes appears to have only a small impact on the estimated canopy scale fluxes.

\section{Discussion}

Although acetaldehyde compensation point measurements in the literature are rare, they have been generally considered to be constant for a given species with small dependencies on season (Rottenberger et al., 2004) and leaf age (Rottenberger et al., 2005) noted. However, evidence sug- gests that changing environmental variables such as root flooding (Rottenberger et al., 2008) and temperature (Karl et al., 2005) may significantly increase acetaldehyde compensation points. The much higher compensation points measured here using branch enclosures in the light compared with the dark suggests that solar radiation and/or temperature also has a large impact on acetaldehyde exchange rates. This is consistent with the suggestion that acetaldehyde production from ethanolic fermentation in leaves is stimulated more than its consumption with increasing light/temperature (Jardine, 2008). While compensation points measured here in the dark (1-3 ppbv) are comparable to those previously reported in the literature $(0.2-6.0 \mathrm{ppbv})$, those in the light far exceed any previously published values ( $>12 \mathrm{ppbv}$ for poplar and $>22$ ppbv for holly oak).

In this paper, we suggest that stomatal/mesophyll resistances influence the acetaldehyde exchange velocity (the slopes of the compensation point curves) while light/temperature influences the acetaldehyde compensation points (x-intercepts of the compensation point curves). Consequently, stomatal resistance does not affect the acetaldehyde compensation point but rather its exchange rate with the atmosphere. Therefore a small stomatal resistance value leads to a high exchange velocity with high emission rates at ambient concentrations below the compensation point and high uptake rates at ambient concentrations above the compensation point. Our results are supported by a complimentary study which found that species dependent differences in acetaldehyde exchange velocities were largely attributed with differences in stomatal resistance (Rottenberger et al., 2008). The direction of the net exchange (net emission or net uptake) can only be determined by the compensation point and ambient concentrations. The net emission rates of sun leaves in the canopy must therefore be caused by an increase in compensation points over the ambient acetaldehyde concentrations as was observed in the branch enclosure studies in the light. Because temperature also increased in the light, we were not able separate light and temperature effects on the compensation point. While temperature has been clearly shown to increase compensation points (Karl et al., 2005), Jardine (2008) has proposed a plausible biochemical mechanism for light enhanced acetaldehyde production. It is now widely accepted that day respiration rates are suppressed relative the night respiration in leaves. However, there is a continuous export of triose phosphates from chloroplasts during photosynthesis. This may lead to enhanced pyruvate concentrations in the cytosol which may then stimulate ethanolic fermentation rates. This same mechanism has been proposed for the transient bursts in acetaldehyde emissions during light to dark transitions (Karl et al., 2002a) termed the pyruvate overflow mechanism. However, Jardine (2008) extended this view by observing bursts of acetaldehyde as well as carbon dioxide, ethanol, and acetic acid following similar light to dark transitions. Therefore, this process was termed light enhanced dark fermentation (LEDF) due to 

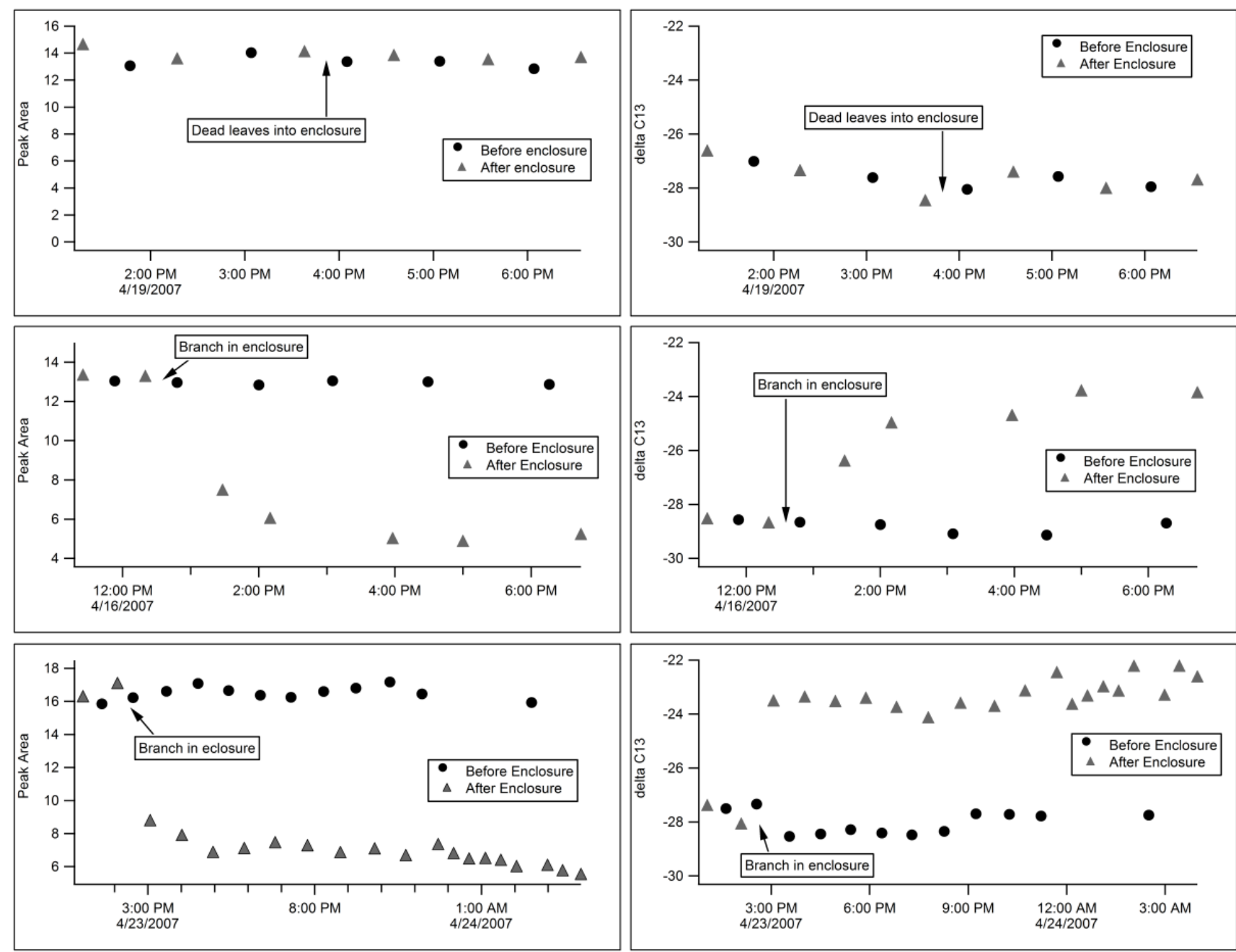

Fig. 6. Carbon isotope fractionation of headspace acetaldehyde during fumigation experiments of dry dead Poplar leaves and live Poplar branches. GC-C-IRMS peak areas (first column) as well as their corresponding $\delta^{13} \mathrm{C}$ values (second column) are plotted versus time during acetaldehyde fumigation experiments in a dynamic branch enclosure.

its strong analogies with the well known, but poorly understood light enhanced dark respiration process (LEDR). The role of light on the compensation point of acetaldehyde and the LEDF and LEDR process deserves additional research.

Even at the extremely high ambient concentrations of acetaldehyde ( $\geq 1000 \mathrm{ppbv}$ ) used in Kondo et al. (1998), no uptake was observed in the dark for several species when stomata were closed, implying that adsorption to the leaf surface or diffusion through the cuticle is insignificant and that the cuticle resistance must be extremely high. Therefore, to a first approximation, acetaldehyde exchange velocities at the branch level are only a function of stomatal and mesophyll resistances acting in series according to Eq. (10).

$v_{e} \approx \frac{1}{R_{S}+R_{m}}$
Our branch enclosure results support this conclusion: The very low acetaldehyde uptake rates by the holly oak branch in the dark with very low transpiration rates indicates that dry deposition to leaf surfaces is not a significant sink for acetaldehyde even at ambient concentrations as high as 27 ppbv. Moreover, fumigation of dry dead poplar leaves with $39.5 \mathrm{ppbv}$ acetaldehyde did not result in significant uptake or carbon isotope fractionation of the gas phase acetaldehyde. The strong correlation between acetaldehyde exchange velocities and transpiration rates in the light and dark for both poplar (Fig. 3) and holly oak (Fig. 4) provides strong evidence for the role of stomatal resistance in influencing the magnitude of both emission and uptake fluxes between plants and the atmosphere. This is because the stomatal resistance to both acetaldehyde and water vapor begins to decrease as the stomata open. Although mesophyll resistance may be 


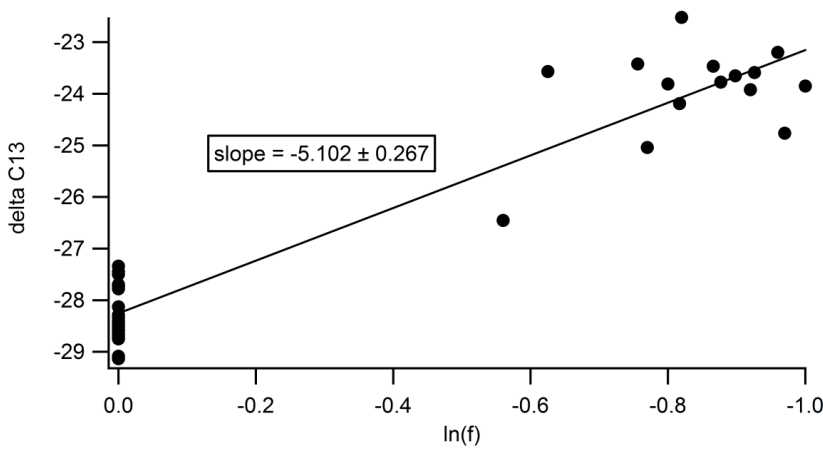

Fig. 7. Estimation of the Kinetic Isotope Effect associated with the uptake of acetaldehyde by poplar branches. The $\delta^{13} \mathrm{C}$ value of the gas-phase acetaldehyde in the headspace (y-axis) are plotted against the natural $\log$ of the fraction of remaining reactant ( $\mathrm{x}$-axis). The slope the this relationship is defined as the kinetic isotope effect.

significant, it is not expected to correlate with transpiration rates if light and temperature are constant. Therefore, the increase in exchange velocity with increasing transpiration rates must be due to a decrease in stomatal resistance. However, it is possible that significant surface sinks may exist on live leaves in the field such as leaf surface water runoff, microbial consumption, or unidentified chemical sinks.

In the dark, while poplar branches were able to maintain significant transpiration rates and acetaldehyde exchange velocities, those of holly oak were very small. This indicates that holly oak stomata close while those of poplar remain partially open during the night. New evidence suggests that like poplar, many plant species do not fully close their stomata at night (Dawson et al., 2007), particularly in ecosystems that are not water-limited. The strong uptake of acetaldehyde at night from whole ecosystems and from shade leaves during the day may therefore be a result of a low compensation point in the dark/shade and non-zero stomatal conductance.

Recently, a physicochemical model has emerged which estimates VOC emission rates from leaves as a function of a source (production) term, the VOC water solubility (Henry's constant), the stomatal resistance, and the (fast and slow) aqueous storage capacity (Niinemets and Reichstein, 2003). Here, we extend this more physicochemical view of the aforementioned model by suggesting that production may also be compensated by physiological consumption within the plant, preventing further plant internal accumulation. If acetaldehyde exchange with plants occurs primarily via stomata, then fluxes $\left(\mathrm{g} \mathrm{m}^{-2} \mathrm{~s}^{-1}\right)$ to and from leaves may be expressed according to Fick's law using Eq. (11),

Flux $=\frac{\Delta C}{R_{S}}$

where $R_{S}$ is the stomatal resistance $\left(\mathrm{s} \mathrm{m}^{-1}\right)$ to acetaldehyde and $\Delta C$ is the acetaldehyde concentration difference $\left(\mathrm{g} \mathrm{m}^{-3}\right)$ between the substomatal cavities and the atmosphere. $\Delta C$ is positive if the concentration in the substomatal cavities is higher than in the atmosphere, leading to net emission, and negative when it is lower, which results in net uptake. No net exchange occurs at the compensation point where $\Delta C$ is zero. Stomatal resistance then can modulate the magnitude of the fluxes if and only if $\Delta C$ and stomatal resistance are at least somewhat independent of each other. That is, if an increase in stomatal resistance leads to a simultaneous and proportional increase in $\Delta C$ due to the accumulation of acetaldehyde during continuous production, there will be no long term stomatal control over acetaldehyde emission rates. This is the case for compounds like isoprene (Fall and Monson, 1992) that lack a significant biological sink. In this well studied system, when stomatal resistance increases, the concentration gradient $(\Delta C)$ increases to overcome the new stomatal limitation. Therefore, $\Delta C$ and $R_{s}$ are not independent of each other and so there is a lack of long-term stomatal control over emission rates. For more water soluble compounds like methanol, while stomatal resistance can influence the short term exchange rates due to the transient sink/source of dissolving/evaporating into/from leaf water, no long term control over emission rates exist (Niinemets and Reichstein, 2003). Like isoprene, this is due to the fact that the emission driving force $\Delta C$ is dependent on the stomatal resistance such that over time $\Delta C$ will increase to compensate for any decrease in stomatal resistance and the net emission flux will be unchanged.

In contrast, we propose that long term stomatal control over exchange rates exists for volatile metabolites such as acetaldehyde that have both significant sources and sinks within plants. The internal concentrations of acetaldehyde may be strongly buffered against large changes in stomatal resistance. For example, if net acetaldehyde emissions are occurring and stomatal resistance increases, then concentrations inside the leaf will increase in the short-term due to reduced flux through the stomata. However, if the internal concentration of acetaldehyde increases, and assuming the sink reactions are dependent on acetaldehyde concentration, the rate of the sink reactions will also increase until a new steady-state is attained; i.e. acetaldehyde concentrations will not continue to increase until they overcome the increased stomatal limitation. Likewise, if net acetaldehyde uptake is occurring and stomatal resistance increases, then internal acetaldehyde concentrations will decrease some due to the reduction of a source (uptake). However, because of continuous production from internal sources and the fact that the internal concentration cannot drop below 0 ppbv, acetaldehyde concentrations do not decrease enough to overcome the stomatal limitation and so the rate of uptake declines.

According to the model by Niinemets and Reichstein (2003), if the net production of acetaldehyde is unaffected by stomatal closure, emission rates should be diminished only briefly by stomatal closure; continuous production would lead to rapid increases in the acetaldehyde 

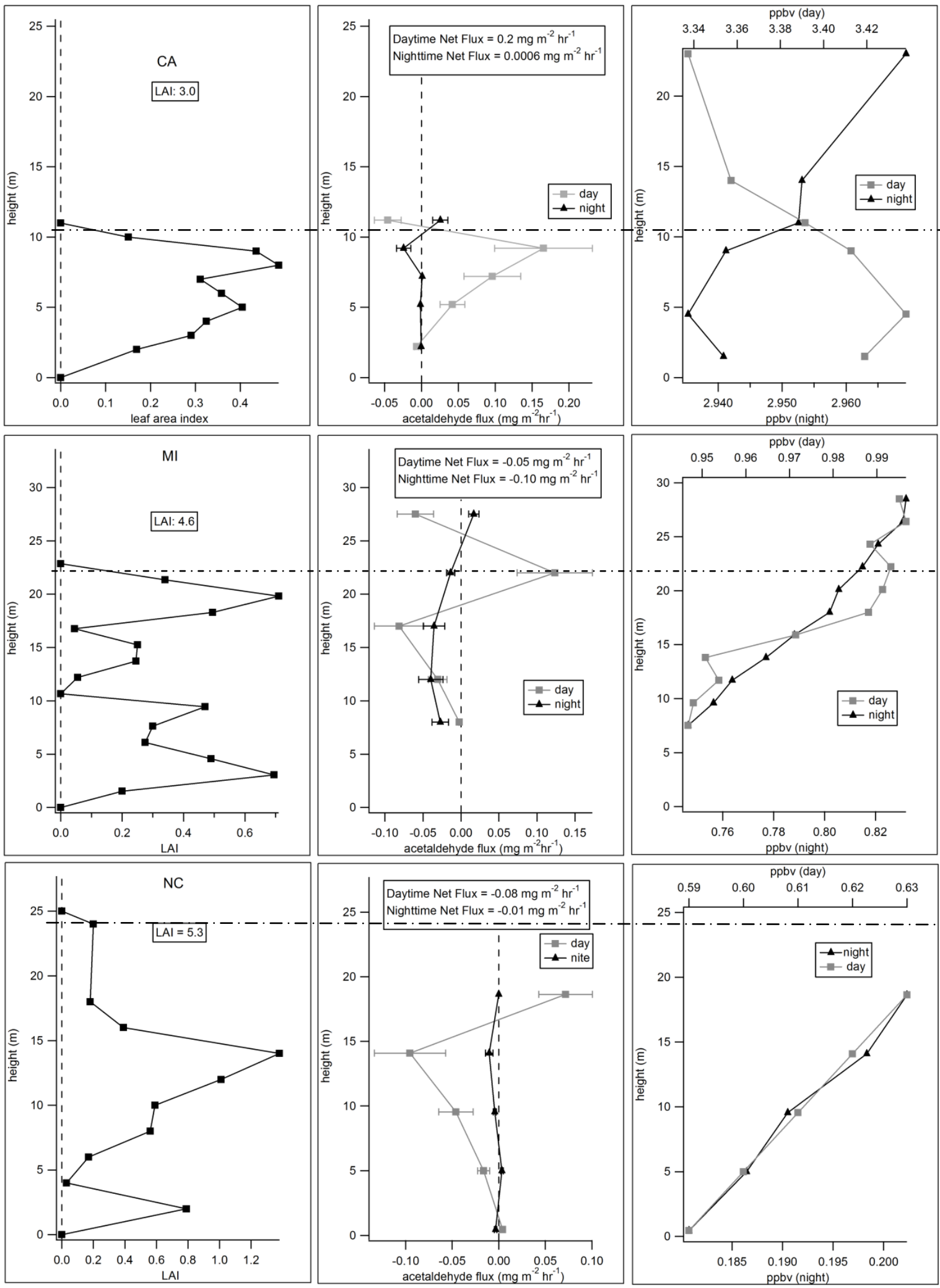

Fig. 8. Fine scale vertical profiles of leaf area index (first column), net acetaldehyde source/sink strength (second column), and ambient concentrations (third column) measured from towers in California (CA), Michigan (MI), and North Carolina (NC). Data from North Carolina is from Karl et al. (2005). Double dashed line is approximate canopy height. 
concentration in the substomatal cavity, overcoming the increase in stomatal resistance and restoring the original flux. This model is incomplete as it does not include the biological $\operatorname{sink}(\mathrm{s})$ for acetaldehyde in plants which limit the extent to which concentration changes can compensate for increased stomatal resistance. However, under ethanol feeding or root anoxia, rates of acetaldehyde production may overwhelm the sinks such that internal acetaldehyde concentrations do increase to very high levels with stomatal closure, and the concentration gradient may, to a first approximation, overcome stomatal limitations. We suggest that like acetaldehyde, exchange rates of a potentially large group of other volatile metabolites such as formaldehyde, formic acid, ethanol, and acetic acid with both a biological source and a sink are also likely to be under long term stomatal control (Kesselmeier, 2001).

Our canopy scale results can be interpreted in the context of this proposed model. Because the ambient concentrations of acetaldehyde measured in this study (0.18-3.44 ppbv) are typically much less than the compensation points measured for poplar and holly oak in the light, net emissions are expected from sun lit leaves as was the case for the upper canopies during the day (Fig. 8). Because solar radiation is rapidly extinguished in a forest canopy, acetaldehyde compensation points are expected to decrease with height. As was observed in the field data, this can lead to a reduction in emission rates and even to net uptake if the compensation point drops below the ambient acetaldehyde concentration as was the case in Michigan and North Carolina. This supports the idea that shade leaves can be a significant sink for tropospheric acetaldehyde. In the CHATS canopy, a lack of significant uptake deeper in the canopy may be related to its short height and rather open nature (LAI=3.0, with trees well separated from each other). A lower LAI necessarily increases the percentage of sunlit versus shade leaves leading to higher compensation points within the canopy. In the CHATS canopy during the day, the ambient concentration where net emissions rates were zero was $3.4 \mathrm{pbbv}$ (at the bottom of the canopy). This is consistent with compensation point measurements on poplar branches made in the dark (1-3 pbbv). However during the day, strong uptake of acetaldehyde occurred within the lower canopies of Michigan and North Carolina with ambient concentrations as low as $0.74-1.0 \mathrm{ppbv}$ and $0.59-0.62 \mathrm{ppbv}$ respectively. This can be explained if compensation points for shade leaves in the field were lower than laboratory compensation point measurements on poplar in the dark (1-3 ppbv). Such low compensation points have been measured for two drought deciduous Amazonian tree species in the field $(0.56 \mathrm{ppbv}, \mathrm{Hy}$ menaea courbaril and 0.32 ppbv, Apeiba tibourbou) (Rottenberger et al., 2004).
Our observations suggest a lower foliar density could result in higher net emissions due to a higher ratio of sun to shade leaves. Consistent with this idea, the low canopy density in California was a strong net source of acetaldehyde throughout the canopy. In contrast, the higher density canopies in North Carolina and Michigan allowed for a switch to be made from a net source to a net sink with decreasing canopy height thereby allowing the lower canopy to act as an effective atmospheric sink for acetaldehyde.

\section{Conclusions}

In this paper, we argue that acetaldehyde exchange rates with plants are fundamentally controlled by three variables: 1) The acetaldehyde compensation point which is a function of light/temperature, 2) ambient acetaldehyde concentrations, and 3) stomatal resistance to acetaldehyde. We suggest that the opening and closing of plant stomata does not have a large affect on internal acetaldehyde concentrations due to continuous production and consumption processes. We therefore argue that unlike isoprene, the driving force for acetaldehyde exchange with plants $(\Delta C)$ is relatively independent of stomatal resistance allowing stomatal behavior to strongly influence exchange rates.

Should primary and secondary anthropogenic sources of acetaldehyde increase in the future, dense forest canopies may act to buffer large increases in atmospheric concentrations. Fumigation studies with extremely high concentrations of acetaldehyde indicates that uptake rates do not saturate until ambient concentrations of $200-1000 \mathrm{ppbv}$ (Kondo et al., 1998). Higher anthropogenic primary and secondary sources likely contributed to the high regional ambient background concentration of acetaldehyde in California ( $>3$ ppbv). Unfortunately, the low canopy leaf area density of the walnut orchard led to high net emission rates during the day due to the lack of significant uptake deeper in the canopy. Therefore, the large fraction of sunlit leaves in low density plant canopies can potentially aggravate regional acetaldehyde pollution by inducing net emissions of acetaldehyde. In contrast, dense forests in non-water limited ecosystems such as in Michigan and North Carolina may be effective sinks for tropospheric acetaldehyde pollution. These forests may therefore effectively mitigate regional air pollution through the net uptake of acetaldehyde. By increasing plant compensation points, future predicted increases in surface temperatures and landscape changes associated with a reduction in foliar density may potentially increase rather than mitigate regional air pollution. However, future increases in drought intensity and duration may increase stomatal resistance thereby reducing the importance of biosphere-atmosphere exchange of acetaldehyde by decreasing exchange velocities. 
Acknowledgements. This work was supported by NSF grant ATM 0303727 (JE Mak), the NSF-funded Biosphere Atmosphere Research and Training (BART) program, and the Atmospheric Chemistry Division at NCAR. The National Center for Atmospheric Research is operated by the University Corporation for Atmospheric Research under the sponsorship of the National Science Foundation. We would like to kindly thank Eric Apel at NCAR for providing gas standards and Ray Fall at CU, Boulder for our many discussions on oxygenated VOCs.

Edited by: A. Neftel

\section{References}

Ammann, C., Brunner, A., Spirig, C., and Neftel, A.: Technical note: Water vapour concentration and flux measurements with PTR-MS, Atmos. Chem. Phys., 6, 4643-4651, 2006, http://www.atmos-chem-phys.net/6/4643/2006/.

Cojocariu, C., Kreuzwieser, J., and Rennenberg, H.: Correlation of short-chained carbonyls emitted from Picea abies with physiological and environmental parameters, New Phytol., 162, 717727, 2004.

Cojocariu, C., Escher, P., Haberle, K. H., Matyssek, R., Rennenberg, H., and Kreuzwieser, J.: The effect of ozone on the emission of carbonyls from leaves of adult Fagus sylvatica, Plant Cell Environ., 28, 603-611, 2005.

Dawson, T. E., Burgess, S. S., Tu, K. P., Oliveira, R. S., Santiago, L. S., Fisher, J. B., Simonin, K. A., and Ambrose, A. R.: Nighttime transpiration in woody plants from contrasting ecosystems, Tree Physiol., 27, 561-575, 2007.

Fall, R. and Monson, R. K.: Isoprene Emission Rate and Intercellular Isoprene Concentration as Influenced by Stomatal Distribution and Conductance, Plant Physiol., 100, 987-992, 1992.

Farquhar, G. D., Ehleringer, J. R., and Hubick, K. T.: Carbon Isotope Discrimination and Photosynthesis, Annu. Rev. Plant Phys., 40, 503-537, 1989.

Hayward, S., Tani, A., Owen, S. M., and Hewitt, C. N.: Online analysis of volatile organic compound emissions from Sitka spruce (Picea sitchensis), Tree Physiol., 24, 721-728, 2004.

Janson, R., De Serves, C., and Romero, R.: Emission of isoprene and carbonyl compounds from a boreal forest and wetland in Sweden, Agr. Forest Meteorol., 98-9, 671-681, 1999.

Jardine, K.: The exchange of acetaldehyde between plants and the atmosphere: Stable carbon isotope and flux measurments, Ph.D. thesis, School of Marine and Atmospheric Science, Stony Brook University, Stony Brook, NY, 169 pp., 2008.

Johnson, B. J. and Dawson, G. A.: A Preliminary-Study of the Carbon-Isotopic Content of Ambient Formic-Acid and $2 \mathrm{Se}-$ lected Sources - Automobile Exhaust and Formicine Ants, J. Atmos. Chem., 17, 123-140, 1993.

Karl, T., Curtis, A. J., Rosenstiel, T. N., Monson, R. K., and Fall, R. Transient releases of acetaldehyde from tree leaves - products of a pyruvate overflow mechanism?, Plant Cell Environ., 25, 11211131, 2002a.

Karl, T., Guenther, A., Spirig, C., Hansel, A., and Fall, R.: Seasonal variation of biogenic VOC emissions above a mixed hardwood forest in northern Michigan, Geophysical Research Letters, 30(23), 2186, doi:10.1029/2003GL018432, 2003
Karl, T., Harley, P., Guenther, A., Rasmussen, R., Baker, B., Jardine, K., and Nemitz, E.: The bi-directional exchange of oxygenated VOCs between a loblolly pine (Pinus taeda) plantation and the atmosphere, Atmos. Chem. Phys., 5, 3015-3031, 2005, http://www.atmos-chem-phys.net/5/3015/2005/.

Karl, T. G., Spirig, C., Rinne, J., Stroud, C., Prevost, P., Greenberg, J., Fall, R., and Guenther, A.: Virtual disjunct eddy covariance measurements of organic compound fluxes from a subalpine forest using proton transfer reaction mass spectrometry, Atmos. Chem. Phys., 2, 279-291, 2002b,

http://www.atmos-chem-phys.net/2/279/2002/.

Kesselmeier, J., Bode, K., Hofmann, U., Muller, H., Schafer, L., Wolf, A., Ciccioli, P., Brancaleoni, E., Cecinato, A., Frattoni, M., Foster, P., Ferrari, C., Jacob, V., Fugit, J. L., Dutaur, L., Simon, V., and Torres, L.: Emission of short chained organic acids, aldehydes and monoterpenes from Quercus ilex L. and Pinus pinea L. in relation to physiological activities, carbon budget and emission algorithms, Atmos. Environ., 31, 119-133, 1997.

Kesselmeier, J.: Exchange of short-chain oxygenated volatile organic compounds (VOCs) between plants and the atmosphere: A compilation of field and laboratory studies, J. Atmos. Chem., 39, 219-233, 2001

Kondo, T., Hasegawa, K., Uchida, R., and Onishi, M.: Absorption of atmospheric C-2-C-5 aldehydes by various tree species and their tolerance to C-2-C-5 aldehydes, Sci. Total Environ., 224, 121-132, 1998.

Kreuzwieser, J., Kuhnemann, F., Martis, A., Rennenberg, H., and Urban, W.: Diurnal pattern of acetaldehyde emission by flooded poplar trees, Physiol. Plantarum, 108, 79-86, 2000.

Kreuzwieser, J., Harren, F. J. M., Laarhoven, L. J. J., Boamfa, I., te Lintel-Hekkert, S., Scheerer, U., Huglin, C., and Rennenberg, H.: Acetaldehyde emission by the leaves of trees - correlation with physiological and environmental parameters, Physiol. Plantarum, 113, 41-49, 2001.

Kreuzwieser, J., Papadopoulou, E., and Rennenberg, H.: Interaction of flooding with carbon metabolism of forest trees, Plant Biology, 6, 299-306, 2004.

Lee, A., Goldstein, A. H., Keywood, M. D., Gao, S., Varutbangkul, V., Bahreini, R., Ng, N. L., Flagan, R. C., and Seinfeld, J. H.: Gas-phase products and secondary aerosol yields from the ozonolysis of ten different terpenes, J. Geophys. Res.-Atmos., 111, D07302, doi:10.1029/2005JD006437, 2006a

Lee, A., Goldstein, A. H., Kroll, J. H., Ng, N. L., Varutbangkul, V., Flagan, R. C., and Seinfeld, J. H.: Gas-phase products and secondary aerosol yields from the photooxidation of 16 different terpenes, J. Geophys. Res.-Atmos., 111, D17305, doi:10.1029/2006JD007050, 2006b.

Lindinger, W. and Hansel, A.: Analysis of trace gases at ppb levels by proton transfer reaction mass spectrometry (PTR-MS), Plasma Sources Sc. T., 6, 111-117, 1997.

Martin, R. S., Villanueva, I., Zhang, J. Y., and Popp, C. J.: Nonmethane hydrocarbon, monocarboxylic acid, and low molecular weight aldehyde and ketone emissions from vegetation in central New Mexico, Environ. Sci. Technol., 33, 2186-2192, 1999.

Miller, L. G., Kalin, R. M., McCauley, S. E., Hamilton, J. T. G., Harper, D. B., Millet, D. B., Oremland, R. S., and Goldstein, A. H.: Large carbon isotope fractionation associated with oxidation of methyl halides by methylotrophic bacteria, P. Natl. Acad. Sci. USA, 98, 5833-5837, 2001. 
Muller, K., Haferkorn, S., Grabmer, W., Wisthaler, A., Hansel, A., Kreuzwieser, J., Cojocariu, C., Rennenberg, H., and Herrmann, H.: Biogenic carbonyl compounds within and above a coniferous forest in Germany, Atmos. Environ., 40, S81-S91, 2006.

Niinemets, U. and Reichstein, M.: Controls on the emission of plant volatiles through stomata: Differential sensitivity of emission rates to stomatal closure explained, J. Geophys. Res.-Atmos., 108(D7), 4208, doi:10.1029/2002JD002620, 2003.

Raupach, M. R.: Applying Lagrangian Fluid-Mechanics to Infer Scalar Source Distributions from Concentration Profiles in Plant Canopies, Agr. Forest Meteorol., 47, 85-108, 1989.

Rottenberger, S., Kuhn, U., Wolf, A., Schebeske, G., Oliva, S. T., Tavares, T. M., and Kesselmeier, J.: Exchange of short-chain aldehydes between Amazonian vegetation and the atmosphere, Ecol. Appl., 14, S247-S262, 2004.

Rottenberger, S., Kuhn, U., Wolf, A., Schebeske, G., Oliva, S. T., Tavares, T. M., and Kesselmeier, J.: Formaldehyde and acetaldehyde exchange during leaf development of the Amazonian deciduous tree species Hymenaea courbaril, Atmos. Environ., 39, 2275-2279, 2005.

Rottenberger, S., Kleiss, B., Kuhn, U., Wolf, A., Piedade, M. T. F., Junk, W., and Kesselmeier, J.: The effect of flooding on the exchange of the volatile $\mathrm{C}_{2}$-compounds ethanol, acetaldehyde and acetic acid between leaves of Amazonian floodplain tree species and the atmosphere, Biogeosciences, 5, 1085-1100, 2008,

http://www.biogeosciences.net/5/1085/2008/.
Schade, G. W. and Goldstein, A. H.: Fluxes of oxygenated volatile organic compounds from a ponderosa pine plantation, J. Geophys. Res.-Atmos., 106, 3111-3123, 2001.

Schade, G. W. and Goldstein, A. H.: Plant physiological influences on the fluxes of oxygenated volatile organic compounds from ponderosa pine trees, J. Geophys. Res.-Atmos., 107(D10), 4082, doi:10.1029/2001JD000532, 2002.

Seco, R., Penuelas, J., and Filella, I.: Short-chain oxygenated VOCs: Emission and uptake by plants and atmospheric sources, sinks, and concentrations, Atmos. Environ., 41, 2477-2499, 2007.

Stroud, C., Makar, P., Karl, T., Guenther, A., Geron, C., Turnipseed, A., Nemitz, E., Baker, B., Potosnak, M., and Fuentes, J. D.: Role of canopy-scale photochemistry in modifying biogenicatmosphere exchange of reactive terpene species: Results from the CELTIC field study, J. Geophys. Res.-Atmos., 110, D17303, doi:10.1029/2005JD005775, 2005.

Villanueva-Fierro, I., Popp, C. J., and Martin, R. S.: Biogenic emissions and ambient concentrations of hydrocarbons, carbonyl compounds and organic acids from ponderosa pine and cottonwood trees at rural and forested sites in Central New Mexico, Atmos. Environ., 38, 249-260, 2004. 